\title{
Arteriovenous Fistula Recirculation in Hemodialysis
}

\author{
Shokouh Shayanpour ${ }^{1}$; Mohammad Faramarzi ${ }^{1, *}$ \\ ${ }^{1}$ Chronic Renal Failure Research Center, Ahvaz Jundishapur University of Medical Sciences, Ahvaz, IR Iran \\ ${ }^{*}$ Corresponding author: Mohammad Faramarzi, Chronic Renal Failure Research Center, Ahvaz Jundishapur University of Medical Sciences, Ahvaz, IR Iran. Tel: +98-9166123980, \\ E-mail: m.faramarzi89@yahoo.com
}

Received: February 1, 2015; Accepted: February 21, 2015

Keywords: Arteriovenous; Recirculation; Hemodialysis

\section{Dear Editor,}

Recently, with great interest we read the review article by Zeraati et al. entitled "A review article: access recirculation among end stage renal disease patients undergoing maintenance hemodialysis" in your most valuable journal (1). The author summarized some of observations about causes and clinical significance of arteriovenous (AV) fistula recirculation, techniques for accurate assessment and main source of pitfall in calculation of access recirculation (AR) (1). Hemodialysis AR occurs when the blood urea concentration in arterial line is lower than that of systemic circulation, indicating that dialyzed blood returning through the venous needle reenters the HD machine through the arterial needle (2).

It is well established that periodic assessment of AR and early detection and treatment of this problem has an important effect in better management of hemodialysis (HD) patients (3-5).

High degrees of AR reduce solute concentration gradients across the dialysis membrane during HD by mixing dialyzed blood with undialyzed blood and reduce the effective clearance of urea and adequacy of HD. Therefore, presence of AR among HD patients leads to significant inadequate dialysis in long-term, which is an important contributor to morbidity and mortality among these patients (6-11). It is also suggested that high degree of AR is one of the surrogate markers of AV fistula inflow problems and periodic assessment of AR can be used as a screening tool for early detection of this problem, which improves long-term AV fistula patency rates (12).

However, it seems that periodic assessment of AR is a neglected issue and most HD centers do not measure AR in HD patients (4).

The most common cause of AR is the presence of stenosis in venous side of the AV fistula, which restricts dialyzed blood venous outflow and the other common cause of AR is inadequate arterial blood flow rate because of AV fistula problems $(3,12)$.

Improper needle placement by HD staff which is due to lack of familiarity with the access anatomy is another cause of backflow or AV fistula recirculation and therefore HD staff have to be educated about the role of close proximity and improper arterial and venous needles placement (13).

An access diagram should be obtained from the surgeon who constructed the AV fistula for appropriate placement of arterial and venous needles by HD staff. The access anatomy can be determined by temporarily occluding the mid portion of AV fistula. After occluding the mid portion of AV fistula, the portion retaining a pulse is the arterial side and the other portion is the venous side of access $(3,12)$.

\section{Acknowledgements}

We wish to thank chronic renal failure research center, which helped us complete this dissertation. Without their continued efforts and support, we could not bring our work to a successful completion.

\section{References}

1. Zeraati A, Beladi Mousavi SS, Beladi Mousavi M. A review article: access recirculation among end stage renal disease patients undergoing maintenance hemodialysis. Nephrourol Mon. 2013;5(2):728-32.

2. Tonelli M, Jindal K, Hirsch D, Taylor S, Kane C, Henbrey S. Screening for subclinical stenosis in native vessel arteriovenous fistulae. J Am Soc Nephrol. 2001;12(8):1729-33.

3. Mousavi SB, Tavazoe M, Hayati F, Sametzadeh M. Arterio-Venous fistula recirculation in hemodialysis: causes and prevalences. Shiraz E Med J. 2010;11(4):219-24.

4. May RE, Himmelfarb J, Yenicesu M, Knights S, Ikizler TA, Schulman G, et al. Predictive measures of vascular access thrombosis: a prospective study. Kidney Int. 1997;52(6):1656-62.

5. Tessitore N, Bedogna V, Poli A, Impedovo A, Antonucci F, Teodori T, et al. Practice patterns in the management of arterio- 


\section{Shayanpour S et al.}

venous fistula stenosis: a northern Italian survey. $J$ Nephrol. 2006;19(2):200-4.

6. Beladi-Mousavi SS, Alemzadeh-Ansari MJ,Alemzadeh-Ansari MH, Beladi-Mousavi M. Long-term survival of patients with end-stage renal disease on maintenance hemodialysis: a multicenter study in Iran. Iran J Kidney Dis. 2012;6(6):452-6.

7. Feily A, Dormanesh B, Ghorbani AR, Moosavi Z, Kouchak M, Cheraghian B, et al. Efficacy of topical cromolyn sodium $4 \%$ on pruritus in uremic nephrogenic patients: a randomized double-blind study in 60 patients. Int J Clin Pharmacol Ther. 2012;50(7):510-3.

8. Beladi-Mousavi SS, Beladi-Mousavi M, Hayati F, Talebzadeh M. Effect of intranasal DDAVP in prevention of hypotension during hemodialysis. Nefrologia. 2012;32(1):89-93.

9. Beladi Mousavi SS, Alemzadeh Ansari MJ, Cheraghian B. Out- come of patients on haemodialysis in Khuzestan, Iran. NDT Plus. 2011;4(2):143-4

10. Tamadon MR, Beladi-Mousavi SS. Erythropoietin; a review on current knowledge and new concepts. J Renal Inj Prev. 2013;2(4):119-21.

11. Beladi Mousavi SS, Sametzadeh M, Hayati F, Fatemi SM. Evaluation of acquired cystic kidney disease in patients on hemodialysis with ultrasonography. Iran J Kidney Dis. 2010;4(3):223-6.

12. Tentori F, Hunt WC, Rohrscheib M, Zhu M, Stidley CA, Servilla K et al. Which targets in clinical practice guidelines are associated with improved survival in a large dialysis organization? J Am Soc Nephrol. 2007;18(8):2377-84.

13. Schneditz D. Recirculation, a seemingly simple concept. Nephro Dial Transpl.1998;13(9):2191-3. 